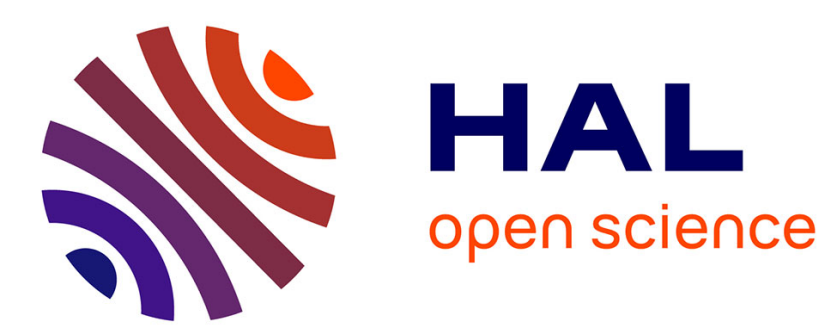

\title{
On the Possible Shapes of the Brain
}

Roberto Toro

\section{To cite this version:}

Roberto Toro. On the Possible Shapes of the Brain. Evolutionary Biology, 2012, 39 (4), pp.600-612. 10.1007/s11692-012-9201-8 . pasteur-01967157

\section{HAL Id: pasteur-01967157} https://hal-pasteur.archives-ouvertes.fr/pasteur-01967157

Submitted on 26 Feb 2019

HAL is a multi-disciplinary open access archive for the deposit and dissemination of scientific research documents, whether they are published or not. The documents may come from teaching and research institutions in France or abroad, or from public or private research centers.
L'archive ouverte pluridisciplinaire HAL, est destinée au dépôt et à la diffusion de documents scientifiques de niveau recherche, publiés ou non, émanant des établissements d'enseignement et de recherche français ou étrangers, des laboratoires publics ou privés. 


\title{
On the possible shapes of the brain
}

\author{
Roberto Toro ${ }^{1,2,3}$ \\ ${ }^{1}$ Human Genetics and Cognitive Functions, Institut Pasteur, Paris, France \\ ${ }^{2}$ CNRS URA 2182 “Genes, synapses and cognition”, Institut Pasteur, Paris, France \\ ${ }^{3}$ Université Paris Diderot, Sorbonne Paris Cité, Human Genetics and Cognitive Functions, Paris, \\ France
}

\section{Address: \\ 25, rue du Docteur Roux \\ 75015 Paris}

France

\section{E-mail: $\underline{\text { rto@pasteur.fr }}$}

\begin{abstract}
The human brain is unique among primates in its apparently random anatomical variability. Here, we argue that this diversity is strongly constrained by developmental processes common to all mammals, and by the mechanics of brain growth. We first study the variability trends across mammals: the phylogenetic and ontogenetic role of the rostro-caudal axis, and the relationships between brain development, the volumes of the grey and white matter, cortical surface area and cortical folding. We discuss in particular the mechanisms of cortical folding and the relationship between folding and the structural and functional organisation of the brain. We examine a computational model that suggest a way in which cortical growth, the geometry and the mechanical properties of the developing brain may explain part of this variability. Growth, and consequently differences in brain volume, appear as a fundamental parameter to understand mammalian neuroanatomical variability. Based on these phylogenetic and theoretical considerations, we turn to the analysis of the variability trends within humans: regional variations in grey and white matter volume and changes in cortical folding. A strong pattern of coordinated variability emerges, where differences in total brain volume are non-linearly related to local neuroanatomical changes. Various aspects of this pattern resemble the trends observed across mammals, suggesting a common mechanism. Finally, we consider the possibility that the changes induced by this global pattern of variability may have a causal influence on the organisation of behaviour, modulating the development of certain cognitive traits or even affecting the susceptibility to psychiatric disorders.
\end{abstract}

\section{Keywords}

Brain development, Brain evolution, Cortical folding, Mathematical modelling, Neuroanatomy

"The great central dome of St Mark's Cathedral in Venice presents in its mosaic design a detailed iconography expressing the mainstays of Christian faith. Three circles of figures radiate out from a central image of Christ: angels, disciples, and virtues. Each circle is divided into quadrants, even though the dome itself is radially symmetrical in structure. Each quadrant meets one of the four spandrels in 
the arches below the dome. Spandrels - the tapering triangular spaces formed by the intersection of two rounded arches at right angles - are necessary architectural by-products of mounting a dome on rounded arches."

SJ Gould and RC Lewontin (1979)

The production of complex shapes is ubiquitous in nature. Physical interactions alone are already able to produce shapes with intricate symmetries, such as in snowflakes, where the form recapitulates the changes in temperature and humidity that affected crystallisation during their fall. In biology, these morphogenetic mechanisms are controlled in a way such that the shape of the individual organism becomes an instance of a developmental pattern sculpted and stabilised during millions of years of evolution.

The study of the evolution of organic shape has been mostly approached from the perspective of the functions that a successfully adapted organism is supposed to fulfil. However, the role played by physical and developmental constraints on the determination and evolution of organic shape has been a matter of interest for a long time (Thompson 1917, Gould and Lewontin 1979, Finlay et al 2001), and more recently the focus of intense research in the field of evolutionary developmental biology (Müller 2007). In the same way as the organisation of the story told by the paintings in central dome of St Mark's Cathedral was certainly influenced by the architectural constraints of the building, biological organisation cannot be isolated from the influence of physical and developmental constraints.

We will consider the role that these constraints may play in the organisation and evolution of the human brain. We will start by briefly discussing some aspects of the diversity of mammalian brain shape, especially concerning the variability of cortical folding. I will then describe a computational model that provides an explanation for some of this variability by taking into account the mechanical constraints of brain growth. Next, we will look at the diversity of human brain shape observed in some of our recent neuroimaging studies. I will argue that an important part of this diversity may be a consequence of changes concomitant with the increase in total brain volume.

But the formation of a brain is that of a unique kind of shape. Here we deal not only with the development and evolution of a complex and precise spatial arrangement of billions of cells and their connections, but also with the genesis of behaviour and cognition. In the last part of this review, we will look at the correlations between genetics, neuroanatomy and cognition, and consider the constraints that the possible shapes of the human brain may impose on cognition.

\section{Diversity of the mammalian brain shape.}

The basic organisation of the brain of placental mammals has remained unchanged for more than 60 million years. Its most distinctive traits, the development of a layered neocortex and the presence of a corpus callosum can be observed as well in shrews as in whales. The degree of elaboration of the different brain regions shows, however, a large variability. For example, rostral structures are disproportionately larger in large mammals compared with small ones.

The phylogenetic rostro-caudal axis is related to a similar gradient of brain development: caudal 
structures are the first to start differentiating, and acquire their adult organisation at an early stage, whereas the more rostral structures have a late, but longer differentiation. Consequently, the most rostral part of the mammalian brain, the neocortex, is the one that displays the largest diversity. Figure 1 illustrates the shape of the brain (mostly neocortex) of several mammalian species. In general, the neocortex of small mammals, such as shrews, mice or squirrels, is smooth (lissencephalic), whereas that of large mammals, such as humans, dolphins or elephants, is profusely folded (gyrencephalic). There are, however, notable exceptions to this rule. The manatee, for example, a marine mammal with a body size comparable with that of a dolphin and a brain volume comparable with that of a chimpanzee, has a completely lissencephalic neocortex.

\section{Figure 1 Here}

Despite the large variability in brain shape among mammals, their geometry reveals a surprising regularity, suggestive of a common developmental process (Prothero and Sundsten 1984, Zhang and Sejnowski 2000). Figure 2 shows in log-log plots, and for different species, the relationship between grey and white matter volume (Fig. 2a), and the relationship between surface and total brain volume (Fig. 2b). We see in Figure 2a that white matter volume, i.e., the volume occupied by axonal connections, is strongly related to grey matter volume. The relationship is nonlinear (allometric formula $W M \sim G M^{1.25}$ ): there is a disproportionately larger volume of white matter in large-brain mammals compared with small-brain mammals. Using dimensional analysis, Zhang and Sejnowski (2000) showed that the relationship between grey and white matter volumes can be deduced from two basic assumptions: that the density of axonal fibres entering and leaving a unit of neocortex is constant, and that the length of connections is optimal. As these two assumptions hold for individual organisms, we should then expect differences in grey/white matter ratio not only across different species, but also for individuals within a single species.

\section{Figure 2 Here}

Figure $2 \mathrm{~b}$ shows that the surface area of the neocortex increases almost proportionally to total brain volume (allometric formula $S \sim V^{0.91}$ ). If different brains were geometrically similar (that is, scaled-up or scaled-down versions one of another) the slope of this regression line should be $2 / 3$. The fact that this slope is closer to 1 means that mammals with large brains have a disproportionately larger neocortex compared with those of small brains. This is due to cortical folding, which makes possible to have more cortical surface inside the same volume. In humans, for example, only $1 / 3$ of the cortical surface is visible, the remaining $2 / 3$ being hidden into folds.

If we observe in more detail the increase in folding with brain size, we see that the differences are not homogeneous throughout the neocortex, but follow a rostro-caudal gradient (Zilles et al 1988, Zilles et al 1989, Rilling and Insel 1999). This rostro-caudal folding gradient can be studied using the gyrification index first proposed by Zilles et al $(1988,1989)$, defined as the ratio between the actual length of the cortical contour in a coronal slice and the length it would have were the brain lissencephalic (similar to the length of the convex envelope of the slice). Figure 3 shows the result of this analysis: on average the degree of folding in humans and great apes is higher towards the more caudal regions of the neocortex, but not significantly different. However, in the more rostral, later developing prefrontal cortex, the degree of folding is significantly higher in human brains (Zilles et al 1988, Rilling and Insel 1999). 
Beyond the differences in degree of folding, the pattern of these folds is very characteristic of the different species, and intriguingly related to the organisation of the neocortex (Welker 1990, Toro and Burnod 2003). The position of deep, early developing, primary folds corresponds frequently with that of cytoarchitectonic, connective or functional boundaries - a correspondence that becomes progressively less clear for the less deep, later developing, secondary and tertiary folds (Brodmann 1909, Fischl et al 2008). Neocortical folding has been often considered as an epiphenomenon of brain development, a reflection of the underlying organisation. We will argue, on the contrary, that folding is a direct outcome of neocortical growth, and then that the mechanical and geometric anisotropies that folding induces may influence and constrain neocortical organisation.

\section{Mechanisms of cortical folding}

Until the second trimester of gestation the neocortex of the human brain is smooth and fairly undifferentiated. Then, processes such as the elaboration of axonal and dendritic arbors and neuroglia, produce a rapid increase in neocortical volume, especially in surface area (Rakic 1988). This is also the time of the emergence of cortical cytoarchitectonic regionalisation, and the development of primary folds. In the adult cortex, different cytoarchitectonic regions can be distinguished based on the cellular composition and relative thickness of its layers (Brodmann 1909). For example, in the primary motor cortex the layers containing neurones whose axons project to the motor neurones in the spinal cord will be greatly expanded and strongly myelinated, whereas the layers receiving afferent fibres will be almost absent. On the contrary, the primary somatosensory cortex will exhibit thinner efferent layers and thicker afferent layers. In primates, the border between the primary motor and somatosensory neocortex corresponds with the bottom of one of the deepest primary folds, the central sulcus. Another deep primary fold, the calcarine sulcus of the occipital lobe, corresponds in many primates with the border between the superior and inferior half-spaces of the primary visual cortex.

In addition, there appears to exist a correspondence between folding patterns and neuronal function, even in cytoarchitectonically homogeneous regions. In the racoon, for example, stimulation of different parts of the forepaws elicit electrical activity in specific regions of the somatosensory neocortex in a topographic manner: neighbouring regions in a forepaw correspond with neighbouring regions in the neocortex. Welker and Campos (1963) have shown that the sensitive regions in the forepaw map into gyri, whereas the limit between palm and fingers, as well as the spaces between fingers, map into sulci. Interestingly, Welker and Campos (1963) observed that even if folding patterns varied among different animals, the relationship between folding and function was conserved in each individual.

The first theories of neocortical folding considered it as a mechanical consequence of the growth of the soft brain tissue inside the rigid cranial vault (Le Gros Clark (1945), and more recently Nie et al (2010)). That this is not the case was first shown by Barron (1950), who studied the role of intra-cranial volume on brain folding by resecting a complete hemisphere in sheep foetuses before the onset of cortical folding. As in many herbivores, the adult sheep brain is profusely folded. If limited intracranial volume were the cause of cortical folding, the operated foetuses should have a lissencephalic brain, as the remaining tissue would have enough space to grow without folding. 
However, at the end of gestation the sheep exhibited a relatively normally folded cortex, conserving most of the characteristic pattern of the sheep brain. This clearly showed that the cause of cortical folding is intrinsic to the brain. A similar, more recent example, was reported by Muckli et al (2009), who described the case of a girl with agenesis of a complete brain hemisphere. As in the experiments of Barron, the remaining hemisphere appeared to be normally folded (and able to support normal cognitive abilities!).

Richmann et al (1975) proposed the first, intrinsically neocortical, mechanical model of folding. They observed that the external pial contour in brain slices was longer than the internal contour of the grey/white matter interface, and hypothesised that the superior cortical layers (I to III) grow faster than the inferior ones (IV to VI). They hypothesised that this differential growth rate was the cause of folding. Whereas this model should be able to produce folds (even if the plausibility of the mechanism has been questioned (Van Essen 1997)), it did not address the way in which a purely mechanical model could explain the correspondence between folding patterns and neocortical organisation.

To explain this correspondence, various researchers have suggested that cortical folding is under direct genetic control. Genetic mechanisms have been shown to play an important role in the early specification of the cortical regionalisation - maybe as early as the beginning of neurogenesis as suggested by Rakic's protomap hypothesis (Rakic 1988). It would be then possible that this same mechanism could somehow determine the developmental dynamics, position and depth of cortical folds. For example, Welker (1990), and more recently Striegel and Hurdal (2009) and Lefèvre and Mangin (2010), have suggested that cortical growth and differentiation are restricted to the future gyral regions. A similar, complementary idea, has been suggested by Smart and McSherry (1986) and more recently by Régis et al (2005), who proposed that during cortical growth the future sulcal regions are genetically programmed to be anchored to the inner structures of the brain, and that only the gyral regions are allowed to expand. Finally, Van Essen (1997), Hilgetag and Barbas (2006) and Geng et al (2009) have proposed that cortical folding is the effect of mechanical tension along cortico-cortical connections. In this latter case, genetic mechanisms should first specify the pattern of cortico-cortical connections, which would then determine the observed folding pattern.

In all these cases, folds are conceived as an epiphenomenon of the processes that specify neocortical organisation. These hypotheses provide a simple answer to the question about the correspondence between cortical folds and cortical regionalisation: folds are genetically programmed to appear where they do. However, many experimental results suggest that neocortical folding can be produced just by globally increasing cortical growth during neurogenesis, either by increasing symmetric divisions (Haydar et al 1999) or decreasing natural cell death (Chenn and Walsh 2002, Kingsbury et al 2003), and without requiring specific, local, gyrogenetic processes. Interestingly then, if neocortical folding were a natural consequence of its growth, and given the correspondence between folding and neocortical organisation, we should expect a causal role of folding on this organisation.

In what follows, I will describe a simple computational model of a growing cortex (Toro and Burnod 2005). We will see how, given the basic geometry and mechanical properties of the cortex, growth alone may be indeed sufficient to produce folding, as well as various other aspects of the dynamics of neocortical folding. 


\section{Morphogenetic model of cortical folding}

Our model tried to mimic a brain at a stage previous to the formation of cortico-cortical connectivity, right after the end of neuronal migration, when the neocortex is still smooth and undifferentiated. We considered, in a very simplified manner, the geometry of the cerebral cortex, its mechanical properties, and its growth:

1. The developing brain was modelled as a cortical layer attached to an inner core of white matter composed of radial fibres, representing radial glia or early cortical-subcortical connections (there were no cortico-cortical connections).

2. Cortex and radial fibres had both elastic (rubber-like) and plastic (clay-like) properties. If an instantaneous force is applied to this type of material it will tend to recover its original form. When released, however, were the force too strong or applied for a long period of time, the material would stay permanently deformed.

3. Cortical growth was modelled by a logistic growth equation: the cortex grew until it reached asymptotically its final size.

Figure 4 Here

We studied the influence of changes in the initial geometry, mechanical properties or regional growth dynamics (A demonstration program and source code can be downloaded at http://brainfolding.sourceforge.net).

In the computer simulations, the model reproduced the main stages of cortical folding observed in real brains (Fig. 4a). During Stage I, the model expanded without folding, while elastic tension in the white matter core increased exponentially. At a certain point, it became energetically less expensive to bend the cortical layer than to keep increasing the tension in the white matter. This is the beginning of Stage II, marked by the quick development of folds all of similar width, and a rapid release of white matter tension. Stage III is a period of slow accommodation of the folding pattern, with some folds eventually fusing. Due to the mechanical plasticity component, the models finally reach a stable state.

The formation of folds in the model did not require any of the specific folding mechanisms that we mentioned earlier, such as resistance opposed by the cranium, differential growth of the inner and outer cortical layers, cortical development genetically circumscribed to pro-gyral or pro-sulcal cortex, or specific cortico-cortical connections. Additionally, the model suggested that some of the features previously regarded as causes of gyrification, could be in fact an effect of growth-driven cortical folding. For example, the apparent anchoring of sulcal fundi, as reported by Smart and McSherry (1986), could be observed in our simulations: in Figure 4a, the position of sulcal fundi at the beginning of the simulation for the smooth model is almost the same as at the end, when folds have fully developed (Fig. 4b).

In our model, increasing growth produces brain shapes where the perimeter of the cortical layer follows linearly the total area of the model (Fig. 4d), similar to the almost linear increase of cortical surface with brain volume across mammalian species (Fig. 2b). But large brains are not always gyrencephalic and small brains are not always lissencephalic. As we saw previously, the manatee brain (Fig. 1) is a well-known example of the former case. Interestingly, the manatee cortex is also 
particularly thick: $4 \mathrm{~mm}$ on average, whereas the human cortex is $2.5 \mathrm{~mm}$ thick on average. This should make the manatee brain especially difficult to bend. Our simulations showed indeed that the width of folds - their wavelength - depends directly on cortical thickness, and that a thick cortex will require more growth than a thin cortex to fold (Fig. 4d).

But if folding were purely mechanical, how to explain the regularities in mammalian folding patterns and their correspondence with the architectonic, functional and connective organisation of the brain? In our simulations, both the timing and the shape of cortical folds were modulated by the initial geometry of the model. When we used a slightly elliptic model instead of a circular one, folds started to develop at the minor axis, and from there to the sides, resembling again the dynamics of primary, secondary and tertiary folds. This rises the possibility that some cortical folds could be induced by the original, bean-like, shape of the brain. Todd (1982) had already observed that the folding pattern of many brains seemed to be related to their global shape. For example, elongated brains will often have folds oriented along the anterior-posterior direction. In the case of the folding pattern of humans, we and others have observed that most primary and secondary folds are also related to the global shape of the brain, being either concentric or perpendicular to the system formed by the corpus callosum and the circular sulci of the insula (Toro and Burnod 2003, Clouchoux et al 2004, Régis et al 2005). To better study the effects of the initial geometry of the cortex on its folding pattern we are currently developing a tridimensional version of the morphogenetic model. In Figure 5a we show an example of folding pattern produced by growth in a model with a slightly ellipsoidal initial geometry. Even if the growth and mechanical parameters are the same everywhere, the model develops folds which follow the shape of the original ellipsoid, being preferentially parallel or perpendicular to its major axis (Fig. $5 b)$.

If the formation and location of a primary fold were determined by the growth and initial geometry of the cortex, then we should consider the possibility that geometric and mechanical developmental constrains may influence the organisation of the brain, and not exclusively the other way around. For example, growth-driven folding produces changes in intrinsic curvature which could act as large-scale anisotropies for the diffusion of morphogens, which could then modulate the patterning of the cerebral cortex, or even favour regional differentiation. Early cortical folding could also, by bringing some regions closer, make it easier for axonal connections to develop between them. The experimental evidence for a causal role of folding in the organisation of the brain is, however, currently missing.

\section{Figure 5 Here}

\section{Diversity of the human brain shape}

The theoretical arguments we have discussed suggest that many aspects of brain folding may result from global cortical growth. The model we have proposed is not species-specific, and it is reasonable to suppose that the mechanical properties of brain tissue are relatively similar across species. Then, the two main determinants of cortical folding should be cortical surface extension (related to the early symmetric division of neuronal progenitors) and cortical thickness (related to the later asymmetric divisions of neuronal progenitors - source of most cortical neurones). But whereas cortical thickness is relatively constant among mammals, there are up to 1000-fold differences in the extension of the cortical surface (Rakic 2009). These differences should be then the major cause of the observed 
diversity in folding among mammals. If this were the case, and given the variability in cortical surface extension within single species, we should observe among individuals of the same species trends of variability similar to those observed across species.

An alternative is what has been named the "mosaic" hypothesis of brain evolution (Barton and Harvey 2000). It states that changes in brain anatomy reflect species-specific modular selection of particular behavioural abilities or cognitive functions. The mosaic hypothesis implies that different brain structures should occupy similar proportions among individuals of the same species, and that there should be a relative independence in the variation of different brain structures.

In this respect, human brain neuroanatomy is especially interesting. Even if the genetic diversity is up to 4 times smaller than that of other great apes (Kaessmann et al 2001), there exists among humans a very large diversity in brain volume and shape. In previous studies, we have investigated the anatomy of the human cerebral cortex in a large population of typically-developing adolescents of French ancestry (Toro et al 2008, 2009) recruited from a relatively geographically isolated population of the Saguenay Lac-Saint-Jean region in Quebec (Pausova et al 2007). We obtained cortical surface reconstructions and lobar grey and white matter volume measurements from magnetic resonance images (MRI) of more than 300 adolescents. We observed a substantial 1.7-fold variability in brain volume. This allowed us to test whether different brain structures occupied the same proportions among humans despite brain volume variability, or if there were among humans variations in regional folding and volume similar to those observed across mammalian species.

Figure 6 Here

\section{Brain size and cortical folding}

Figure 6 shows the relationship between cortical surface area and brain volume in a log-log plot, similar to the inter-species plot in Figure $2 b$. If human brains were geometrically similar, the data points should follow a regression line with slope of $2 / 3$. We observed, however, a regression slope of 0.85 , significantly larger than $2 / 3$. This means that large human brains had a disproportionately larger cortical surface area. Indeed, if the volume of the smallest brain in our sample were scaled up to match the volume of the largest brain in our sample, it would have $20 \%$ less cortical surface. The relationship is extremely strong, the correlation between hemispheric volume and cortical surface is of $\mathrm{r}=0.93$, explaining $87 \%$ of the variance.

Next we looked at the average degree of folding, as well as the changes in folding related to brain size. We developed a local, tridimensional, estimate of the degree of folding by extending the gyrification index of Zilles et al (1988): At every point of the cortex we computed the amount of surface area contained in a small sphere (typically, $20 \mathrm{~mm}$ radius); if the cortex were completely smooth, the surface area inside the small sphere should not be too different from that of a disc with the same radius; thus, for every point in the cortex, we estimated folding as a "surface ratio" between the cortical surface area inside the sphere, and the area of its disc (Toro et al 2008). Figure 7a shows the average degree of folding in our population, which increases with a rostro-caudal gradient, similar to the gradient observed in inter-species comparisons (Fig. 3).

We observed that the increased cortical folding in subjects with large brains was not homogeneous 
throughout the cortex, but especially significant towards the prefrontal cortex. We used multiple regression to determine how the variations in the degree of folding changed relative to brain size. We observed a gradient, opposite to that of the average degree of folding. Like in the comparison between humans and great apes (Fig. 3), the differences in degree of folding relative to brain size among our subjects were especially significant towards the prefrontal cortex, and less significant towards the occipital pole (Fig. 7b).

Figure 7 Here

\section{Brain size and regional volumes}

Figure 8 shows the variability in grey and white matter volumes in the frontal, parietal, occipital and temporal lobes. Instead of a bivariate comparison between grey and white matter volumes only (as in Fig. 2a), we used a multivariate allometric analysis to examine the relationship between all 8 regional volumes at the same time (Toro et al 2009). There was a strong pattern of covariation between the volume of the different regions: the average correlation was $\mathrm{r}=0.92$ among white matter regions, $\mathrm{r}=0.82$ among grey matter regions, and $\mathrm{r}=0.36$ between grey and white matter regions (Fig. $8 \mathrm{~b}$ ).

This covariation pattern produced a strong multivariate allometric relationship (obtained from the first principal component of the covariance matrix, after Jolicoeur (1963)), which accounted for $72 \%$ of the total variance. The covariation pattern is summarised in Figure 8c; it shows the way in which the proportions of grey and white matter volume in all four lobes change in subjects with total cerebral volume from $850 \mathrm{~cm}^{3}$ to $1,250 \mathrm{~cm}^{3}$. We observe that the proportion occupied by white matter increases with brain volume (positive allometry), similar to the inter-species comparison (Fig. 2a). The general positive allometry of the white matter volume is likely related to the global increase in cortical surface area with brain volume, and regional differences are likely related to the rostro-caudal gradient in cortical expansion. Furthermore, we observe that the volume of specific brain regions cannot change independently of the rest of the brain, which is likely due to their profuse interconnection: the variability in regional volumes appears to follow a very constrained pattern, instead of being a mosaic of independent modules.

Figure 8 Here

\section{Possible shapes, possible behaviours}

We have seen that growth, geometry and the mechanical properties of nervous tissue seem to define a non-linear, global pattern of brain variability that strongly constrains the possible shapes of the brain across species, but also within a single species. These mechanical developmental constraints should influence and modulate the architectonic and connective organisation of the brain, but should also affect its function, behaviour and cognition. We could argue, however, that the mammalian brain, and especially the neocortex, is capable of prodigious plasticity and resilience, which insulate its functional organisation from material vicissitudes. Huffman et al (1999) have shown, for example, that the normal number and topography of neocortical cytoarchitectonic areas develop in short-tailed opossums even after resecting 3/4 of their cortical surface. Von Melchner et al (2000) have shown that ferrets are able to use their auditory cortex for seeing, after visual afferents had been surgically rewired to auditory cortex. And even in humans, subjects with extreme cases of hydrocephaly 
(Feuillet et al 2007) or hemispheric agenesis (Muckli et al 2009) are able to develop a normal cognition. With this in mind, I will present some examples suggesting that the neuroanatomical changes related to the global pattern of brain variability can have a causal influence in the organisation of behaviour, affecting the development of certain cognitive traits or even biasing the susceptibility to psychiatric disorders.

A first example is given by the architectonic and behavioural differences associated with the presence in some subjects of an extra cortical fold. The medial surface of the human frontal lobe is a major structure of the network supporting executive function (Fornito et al 2004). In this region, and likely related to differences in brain volume, some subjects develop a single sulcus parallel to the corpus callosum, the cingulate sulcus, whereas some others (30-60\%) have a supplementary one, the paracingulate sulcus. The presence or absence of the paracingulate sulcus has been associated with differences in the cytoarchitecture of the region (Vogt et al 1995), but also with significant differences in the performance of verbal and non-verbal executive tasks (Fornito et al 2004).

Another example is provided by the neuroanatomical and behavioural correlates of a widely studied single-nucleotide polymorphism (SNP) of the pro-BDNF gene, the Val66Met variation. BDNF, the brain-derived neurotrophic factor, plays an important role in synaptic plasticity and neuronal survival. Most subjects of european ancestry are homozygotes for the allele encoding a Valine amino acid at codon 66, but in about 35\% of the cases, at least one allele is replaced by a Metionin amino acid. Several studies have reported that Val/Val homozygotes appear to have moderately higher density of prefrontal grey matter and larger hippocampal volume (Pezawas et al 2004, Bueller et al 2006, Frodl et al 2007). We genotyped this polymorphism in our subject group, and whereas we did find the previously reported regional differences, we also observed that the covariation pattern was not different between groups $(\mathrm{P}=0.81,10000$ permutations). In fact, the regional differences were all the consequence of a small, but statistically significant, difference in total brain volume, $\sim 30 \mathrm{~cm}^{3}$ larger in the Val/Val homozygotes (Fig. 8d). Interestingly, these differences - likely resulting from a moderate difference in brain volume - had been previously associated with various behavioural differences: in episodic memory, in the score of neuroticism (a fundamental personality trait), but also in the susceptibility to psychiatric disorders such as bipolar disorder or major depression (Neves-Pereira et al 2002, Sklar et al 2002, Sen et al 2003, Egan et al 2003, Hariri et al 2003, Frodl et al 2007).

Would it be possible that large and small brains are differently able to compensate for a pathogenic event, and then, differently susceptible to develop a psychiatric condition? It has been observed that patients with autism spectrum disorders (ASD) have, on average, a larger brain volume and a higher incidence of macrocephaly (20\%) compared with control populations (4\%). It has been often assumed that this "overgrowth" is an effect of the pathology. But non-affected mothers and fathers of ASD patients also exhibit a high incidence of macrocephaly, similar to that of their affected offspring (Lainhart et al 2006), suggesting that the large brain volume may not be a sign of pathology, but an inherited trait. Neuroimaging studies have shown that ASD patients present in addition with an increased frontal white matter volume (Herbert et al 2004, Carper and Courchesne 2005), a larger frontal grey matter volume (Amaral et al 2008) and higher degree of prefrontal folding (Herbert et al 2004, Courchesne and Pierce 2005). As we have seen, all these local differences are the expected outcomes of a larger total brain volume.

The increase in brain size is one of the most evident features of human brain evolution. Among 
mammals, primates have particularly large brains in relation to body size, and humans have the largest brains among all primates (Jerison 1973, Passingham 1973). The cranial volume of the Homo genus has more than doubled during the two million years that separate us from Homo Habilis, and the cortical surface may have expanded at least in the same proportion. Our results suggest that this growth should lead to a coordinated change in brain anatomy, and in particular to a natural expansion of the prefrontal cortex. The prefrontal cortex is involved in various high-level cognitive functions, and its expansion has been regarded as a major evolutionary modification leading to the emergence of human intelligence. Badre and D'Esposito (2009) have proposed that the frontal cortex is hierarchically organised along the rostro-caudal axis, with the more frontal regions adding progressively more abstract levels of cognitive control. For example, activity in the primary motor cortex will directly translate into concrete movements, which are then composed into movement patterns, and then into progressively more complex behaviours as we advance towards the frontal pole. As the neocortex expands, its cytoarchitectonic regions not only become larger, but seem also to segregate into different, more specialised regions (Krubitzer 2007, O'Leary and Sahara 2008). Increasing the extent and then the elaboration of the prefrontal regions in humans may have permitted the development of new levels of abstraction, and allowed us to develop richer cognitive functions such as language, planning and creative thinking (Goldman-Rakic 1996, Wood and Grafman 2003, Petrides 2005).

\section{References}

Amaral, D.G., Schumann, C.M., Nordahl, C.W. (2008) Neuroanatomy of autism. Trends Neurosci 31(3):137-145.

Badre, D., D'Esposito, M. (2009) Is the rostro-caudal axis of the frontal lobe hierarchical?. Nat Rev Neurosci 10:659-669.

Barron, D. (1950) An experimental analysis of some factors involved in the development of the fissure pattern of the cerebral cortex. J Exp Zool 113:553-581.

Barton, R.A., Harvey, P.H. (2000) Mosaic evolution of brain structure in mammals. Nature 405:1055-1058.

Brodmann, K. (1909) Vergleichende Lokalisationslehre der Grosshirnrinde in ihren Prinzipien dargestellt auf Grund des Zellenbaues. Johann Ambrosius Barth, Leipzig.

Bueller, J.A., Aftab, M., Sen, S., Gomez-Hassan, D., Burmeister, M., Zubieta, J.K. (2006) BDNF Val66Met allele is associated with reduced hippocampal volume in healthy subjects. Biol Psychiatry 59:812-815.

Carper, R.A., Mosesc, P., Tiguea, Z.D., Courchesne, E. (2002) Cerebral lobes in autism: early hyperplasia and abnormal age effects. Neuroimage 16(4):1038-1051.

Chenn, A., Walsh, C.A. (2002) Regulation of cerebral cortical size by control of cell cycle exit in neural precursors. Science 297:365-369.

Clouchoux, C., Coulon, O., Cachia, A., Rivière, D., Mangin, J.F., Régis, J.M. (2004) Towards an anatomically meaningful parameterization of the cortical surface. In Christian Barillot, David Haynor, and Pierre Hellier, editors, Proc. of MICCAI'04, LNCS, Saint-Malo, France, Sep. 2004. Springer Verlag.

Courchesne, E., Pierce, K. (2005) Why the frontal cortex in autism might be talking only to itself: local over-connectivity but long-distance disconnection. Curr Opin Neurobiol 15(2):225-230.

Egan, M., Kojima, M., Callicott, J., Goldberg, T., Kolachana, B., Bertolino, A., Zaitsev, E., Gold, B., Goldman, D., Dean, M. (2003) The BDNF val66met polymorphism affects activity-dependent secretion of BDNF and human memory and hippocampal function. Cell 112(2):257-269. 
Feuillet, L., Dufour, H., Pelletier, J. (2007) Brain of a white-collar worker. Lancet 370(9583):262.

Finlay, B.L., Darlington, R.B., Nicastro, N. (2001) Developmental structure in brain evolution. Behav Brain Sci 24:263-278.

Fischl, B., Rajendran, N., Busa, E., Augustinack, J., Hinds, O., Yeo, B.T., Mohlberg, H., Amunts, K., Zilles, K. (2008) Cortical Folding Patterns and Predicting Cytoarchitecture. Cereb Cortex 18(8):1973-1980.

Fornito, A., Yücel, M., Wood, S., Stuart, G.W., Buchanan, J.A., Proffitt, T., Anderson, V., Velakoulis, D., Pantelis, C. (2004) Individual Differences in Anterior Cingulate/Paracingulate Morphology Are Related to Executive Functions in Healthy Males. Cereb Cortex 14(4): 424-431.

Frodl, T., Schüle, C., Schmitt, G., Born, C., Baghai, T., Zill, P., Bottlender, R., Rupprecht, R., Bondy, B., Reiser, M., Möller, H.J., Meisenzahl, E.M. (2007) Association of the brain-derived neurotrophic factor Val66Met polymorphism with reduced hippocampal volume in major depression. Arch Gen Psychiatry 64:410-416.

Geng, G., Johnston, L.A., Yan, E., Britto, J.M., Smith, D.W., Walker, D.W., Egan, G.F. (2009) Biomechanisms for modelling cerebral cortical folding. Med Image Anal 13(6):920-30.

Goldman-Rakic, P.S. (1996) The prefrontal landscape: implications of functional architecture for understanding human mentation and the central executive. Phil Trans $\mathrm{R}$ Soc Lond B 351:1445-1453.

Gould, S.J., Lewontin, R.C. (1979) The spandrels of San Marco and the Panglossian paradigm: a critique of the adaptationist programme. Proc R Soc Lond B 21:581-598.

Hariri, A.R., Goldberg, T.E., Mattay, V.S., Kolachana, B.S., Callicott, J.H., Egan, M.F., Weinberger, D.R. (2003) Brain-derived neurotrophic factor val66met polymorphism affects human memory-related hippocampal activity and predicts memory performance. J Neurosci 23:6690-6694.

Haydar, T.F., Kuan, C.Y., Flavell, R.A., Rakic, P. (1999) The role of cell death in regulating the size and shape of the mammalian forebrain. Cereb Cortex 9:621-626.

Herbert, M.R., Ziegler, D.A., Makris, N., Filipek, P.A., Kemper, T.L., Normandin, J.J., Sanders, H.A., Kennedy, D.N., Caviness, V.S. Jr (2004) Localization of white matter volume increase in autism and developmental language disorder. Ann Neurol 55(4):530-540.

Hilgetag, C.C., Barbas, H. (2006) Role of mechanical factors in the morphology of the primate cerebral cortex. PLoS Comput Biol 2(3):e22.

Huffman, K.J., Molnár, Z., Van Dellen, A., Kahn, D.M., Blakemore, C., Krubitzer, L. (1999) Formation of cortical fields in a reduced cortical sheet. J Neurosci 19(22):9939-9952.

Jerison, H.J. (1973) Evolution of the brain and intelligence. New York: Academic Press.

Jolicoeur, P. (1963) The multivariate generalization of the allometry equation. Biometrics 19:497-499.

Kaessmann, H., Wiebe, V., Weiss, G., Pääbo, S. (2001) Great ape DNA sequences reveal a reduced diversity and an expansion in humans. Nature Genet 27:155-156.

Kingsbury, M., Rehen, S., Contos, J., Higgins, C., Chun, J. (2003) Non-proliferative effects of lysophosphatidic acid enhance cortical growth and folding. Nat Neurosci 6:1292-1299.

Krubitzer, L. (2007) The magnificent compromise: cortical field evolution in mammals. Neuron 56(2):201-208.

Lainhart, J.E., Bigler, E.D., Bocian, M., Coon, H., Dinh, E., Dawson, G., Deutsch, C.K., Dunn, M., Estes, A., Tager-Flusberg, H., Folstein, S., Hepburn, S., Hyman, S., McMahon, W., Minshew, N., Munson, J., Osann, K., Ozonoff, S., Patricia, R., Rogers, S., Sigman, M., Spence, M.A., Stodgell, C.J., Volkmar, F. (2006) Head circumference and height in autism: A study by the collaborative program of excellence in autism. Am J Med Genet A, 140(21):2257-2274. 
Lefèvre, J., Mangin, J.F. (2010) A Reaction-Diffusion Model of Human Brain Development. PLoS Comput Biol 6(4):e1000749.

Le Gros Clark, W. (1945) Deformation patterns on the cerebral cortex. In: essays on growth and form. Oxford: Oxford University Press.

Muckli, L., Naumer, M.J., Singer, W. (2009) Bilateral visual field maps in a patient with only one hemisphere. Proc Natl Acad Sci 106(31):13034-13039.

Müller GB (2007) Evo-devo: extending the evolutionary synthesis. Nat Rev Genet 8:943-949.

Neves-Pereira, M., Mundo, E., Muglia, P., King, N., Macciardi, F., Kennedy, J. (2002) The brain-derived neurotrophic factor gene confers susceptibility to bipolar disorder: evidence from a family-based association study. Am J Hum Genet 71(3):651-655.

Nie, J., Guo, L., Li, G., Faraco, C., Miller, L.S., Liu, T. (2010)A computational model of cerebral cortex folding, J Theor Biol 264(2):467-478.

O'Leary, D. and Sahara, S. (2008) Genetic regulation of arealization of the neocortex. Curr Opin Neurobiol 18:90-100.

Passingham, R.E. (1973) Anatomical differences between the neocortex of man and other primates. Brain Behav Evol 7:337-359.

Pausova, Z., Paus, T., Abrahamowicz, M., Almerigi, J., Arbour, N., Bernard, M., Gaudet, D., Hanzalek, P., Hamet, P., Evans, A.C., et al (2007) Genes, maternal smoking, and the offspring brain and body during adolescence: design of the Saguenay youth study. Hum Brain Mapp 28:502-518.

Petrides, M. (2005) Lateral prefrontal cortex: architectonic and functional organization. Phil Trans R Soc B 360:781-795.

Pezawas, L., Verchinsky, B.A., Mattay, V.S., Callicott, J.H., Kolachana, B.S., Straub, R.E., Egan, M.F., Meyer-Lindenberg, A., Weinberger, D.R. (2004) The brain-derived neurotrophic factor val66met polymorphism and variation in human cortical morphology. J Neurosci 24:10099-10102.

Prothero, J.W., Sundsten, J.W. (1984) Folding of the cerebral cortex in mammals. A scaling model. Brain Behav Evol 24:152-167.

Rakic, P. (1988) Specification of cerebral cortical areas. Science 241:170-176.

Rakic P (2009) Evolution of the neocortex: a perspective from developmental biology. Nat Rev Neurosci 10:724-735.

Régis, J.M., Mangin, J.F., Ochiai, T., Frouin, V., Rivière, D., Cachia, A., Tamura, M., Samson, Y. (2005). "Sulcal root" generic model: a hypothesis to overcome the variability of the human cortex folding patterns. Neurol Med Chir (Tokyo). 45:1-17.

Richman, D.P., Stewart, R.M., Hutchinson, J.W., Caviness, V.S. (1975) Mechanical model of brain convolutional development. Science 189:18-21.

Rilling, J.K., Insel, T.R. (1999) The primate neocortex in comparative perspective using magnetic resonance imaging. J Hum Evol 37:191-223.

Sen, S., Nesse, R.M., Stoltenberg, S.F., Li, S., Gleiberman, L., Chakravarti, A., Weder, A.B., Burmeister, M. (2003) A BDNF coding variant is associated with the NEO personality inventory domain neuroticism, a risk factor for depression. Neuropsychopharmacology 28(2):397-401.

Sklar, P., Gabriel, S.B., McInnis, M.G., Bennett, P., Lim, Y.M., Tsan, G., Schaffner, S., Kirov, G., Jones, I., Owen, M., Craddock, N., DePaulo, J.R., Lander, E.S. (2002) Family-based association study of 76 candidate genes in bipolar disorder: BDNF is a potential risk locus. Brain-derived neutrophic factor. Mol Psychiatry 7(6):579-593.

Smart, I., McSherry, G. (1986) Gyrus formation in the cerebral cortex in the ferret. I. Description of the external changes. J Anat 146:141-152.

Striegel, D.A., Hurdal, M.K. (2009) Chemically based mathematical model for development of 
cerebral cortical folding patterns. PLoS Comput Biol 5(9): e1000524.

Todd, P. (1982) A geometric model for the cortical folding pattern of simple folded brains. J Theor Biol 97:529-538.

Thompson, D.W. (1917) On growth and form. Cambridge University Press.

Toro, R., Burnod, Y. (2003) Geometric atlas: modeling the cortex as an organized surface. NeuroImage 20(3):1468-1484.

Toro, R., Burnod, Y. (2005) A morphogenetic model for the development of cortical convolutions. Cereb Cortex 15:1900-1913.

Toro, R., Perron, M., Pike, B., Richer, L., Veillette, S., Pausova, Z., Paus, T. (2008) Brain size and folding of the human cerebral cortex. Cereb Cortex 18(10):2352-2357.

Toro, R., Chupin, M., Garnero, L., Leonard, G., Perron, M., Pike, B., Pitiot, A., Richer, L., Veillette, S., Pausova, Z., et al. (2009) Brain volumes and val66met polymorphism of the BDNF gene: local or global effects? Brain Struct Funct 213(6):501-509.

Van Essen, D.C. (1997) A tension-based theory of morphogenesis and compact wiring in the central nervous system. Nature 385:313-318.

Vogt, B.A., Nimchinsky, E.A., Vogt, L.J., Hof, P. (1995) Human cingulate cortex: surface features, flat maps, and cytoarchitecture. J Comp Neurol 359:490-506.

Von Melchner, L., Pallas, S.L., Sur, M. (2000) Visual behaviour mediated by retinal projections directed to the auditory pathway. Nature 404(6780):871-876.

Welker, W. (1990) Why does cerebral cortex fissure and fold? A review of determinants of gyri and sulci. In: Jones EG, Peters A, editors. Cerebral cortex Vol. 8b. New York: Plenum Press.

Welker, W., Campos, G. (1963) Physiological significance of sulci in somatic sensory cerebral cortex in mammals of the family procyonidae. J Comp Neurol 120:19-36.

Wood, J.N., Grafman, J. (2003) Human prefrontal cortex: processing and representational perspectives. Nat Rev Neurosci 4:139-147.

Zhang, K., Sejnowski, T.J. (2000) A universal scaling law between gray matter and white matter of cerebral cortex. Proc Natl Acad Sci USA 97(10):5621-5626.

Zilles, K., Armstrong, E., Moser, K.H., Schleicher, A., Stephan, H. (1989) Gyrification in the cerebral cortex of primates. Brain Behav Evol 34:143-150.

Zilles, K., Armstrong, E., Schleicher, A., Kretschmann, H.J. (1988) The human pattern of gyrification in the cerebral cortex. Anat Embryol (Berl) 179:173-179. 
Fig. 1. Diversity of the mammalian brain shape. Lateral aspect of various mammalian brains, drawn at the same scale. Based on images from http://brainmuseum.org.

Fig. 2. Regularities in the shape of the mammalian brain. (a) White matter volume versus grey matter volume for across mammals (log-log plot). If the proportion of white matter and grey matter were constant, data should follow the segmented line with slope 1 . However, white matter volume increases disproportionately to total brain volume, with a slope $=1.23$. Adapted from Zhang and Sejnowski (2000). (b) Cortical surface area versus brain volume for across mammals (log-log plot). If mammalian brains were geometrically similar, the relationship between their cortical surface and volume should follow the segmented line with slope $2 / 3$. However, cortical surface area increases disproportionately with brain volume, with a slope $=0.91$. Adapted from Prothero and Sundsten 1984).

Fig. 3. Rostrocaudal gradient of cortical folding in humans and other great apes. The degree of folding decreases from the caudal part of the brain to the rostral part. When the degree of folding is compared between humans and other great apes, significant differences are found mainly towards the prefrontal cortex. Degree of folding estimated using the gyrification index (Zilles et al 1988) in serial coronal slices. Adapted from Zilles et al 1989.

Fig. 4. Morphogenetic model of cortical folding in two dimensions. (a) Formation of folds in the morphogenetic model due to cortical growth follows three stages, resembling the development of gyrencephalic brains. Stage I, symmetric growth: the model grows without folding. Stage II, development: folds start to develop rapidly. Stage III, accommodation: fold slowly accommodate, eventually fusing. (b) Position of gyri and sulci in the model. After the formation of folds, the position of the sulcal fundi is similar to their position at the beginning. (c) Dynamics of folding formation following a perturbation of the model. The first fold to develop (curve a) is the deepest fold at the end of the simulation. Further folds (b-e) will be progressively less deep, resembling the formation of primary, secondary and tertiary folds in gyrencephalic brains. (d) Relationship between the perimeter of the cortical layer and the total area of the model for models with different cortical layer thicknesses. Before the formation of folds, all models are geometrically similar, following a regression line with slope $=1 / 2$, the value for isometric scaling of area and perimeter. After the formation of folds, perimeter and area increase almost proportionally. The thickest models require higher levels of growth to start folding and develop, on average, less folds. White dots show the thickest models, black dots the thinner models, and grey dots are intermediate. For the same initial external perimeter, white models developed 9.5 folds on average, grey models 11.5 folds on average and black models 13.1 folds on average. Adapted from Toro and Burnod (2005).

Fig. 5. Morphogenetic model of cortical folding in three dimensions. (a) Development of folds in a model with an ellipsoidal initial shape. As in the two-dimensional case, the model started by growing without folding, then folds start to develop suddenly, followed by a long stage of accommodation. (b) Different views of the folded model. The orientation of folds at the end of the simulation tends to follow the global shape of the model, resembling the folding patterns of gyrencephalic mammals.

Fig. 6. Diversity of cortical surface area versus brain volume among humans. If human brains were geometrically similar, the relationship between their cortical surface and volume should follow 
the segmented line with slope $2 / 3$. However, as across mammalian species, cortical surface area increases disproportionately with brain volume with a slope $=0.85$. Adapted from Toro et al (2008).

Fig. 7. Rostrocaudal gradient of cortical folding in humans. The average degree of folding decreases from the caudal (occipital) part of the brain to the rostral (frontal) part (left). When the local degree of folding is correlated with brain size among humans, the most significant differences are found in the prefrontal cortex, gradually decreasing towards the occipital lobe (right). Local degree of folding estimated using the surface ratio index. Adapted from Toro et al (2008).

Fig. 8. Diversity of grey and white matter volumes in the frontal, parietal, occipital and temporal lobes among humans. The proportion of different regional volumes changes with total brain size (a) Illustration of the regions measured, top: frontal, parietal, occipital and temporal lobes, bottom: grey and white matter (subcortical structures were not included in the measurements). (b) Pattern of correlated change in regional brain volumes. The figure shows strong correlations in white matter volumes ( $\mathrm{r}=0.92$ on average) and grey matter volumes ( $\mathrm{r}=0.82$ on average), as well as substantial grey-white matter correlations ( $\mathrm{r}=0.36$ on average). (c) The pattern of variation in the proportion of regional volumes with respect to brain volume, based on the first principal component of the covariance matrix (explaining $72 \%$ of the variance) shows a non-linear relationship between regional volumes and the total brain volume. In particular, the proportion occupied by the white matter increases with brain volume, resembling the trend observed across species. The vertical lines indicate the average brain volume of Met and Val subjects. (d) The regional differences observed between Val homozygotes and Met carriers seem to be due only to the global difference in brain volume, and not to local effects of BDNF genotype on volume. The table shows that the differences predicted from the difference in total brain volume fall within the $95 \%$ confidence interval of the observed difference. $\mathrm{Fw}=$ Frontal white, $\mathrm{Pw}=$ Parietal white, $\mathrm{Ow}=$ Occipital white, $\mathrm{Tw}=$ Temporal white, $\mathrm{Fg}=$ Frontal grey, $\mathrm{Pg}=$ Parietal grey, $\mathrm{Og}=\mathrm{Occipital}$ grey, $\mathrm{Tg}=$ Temporal grey. Adapted from Toro et al (2009). 


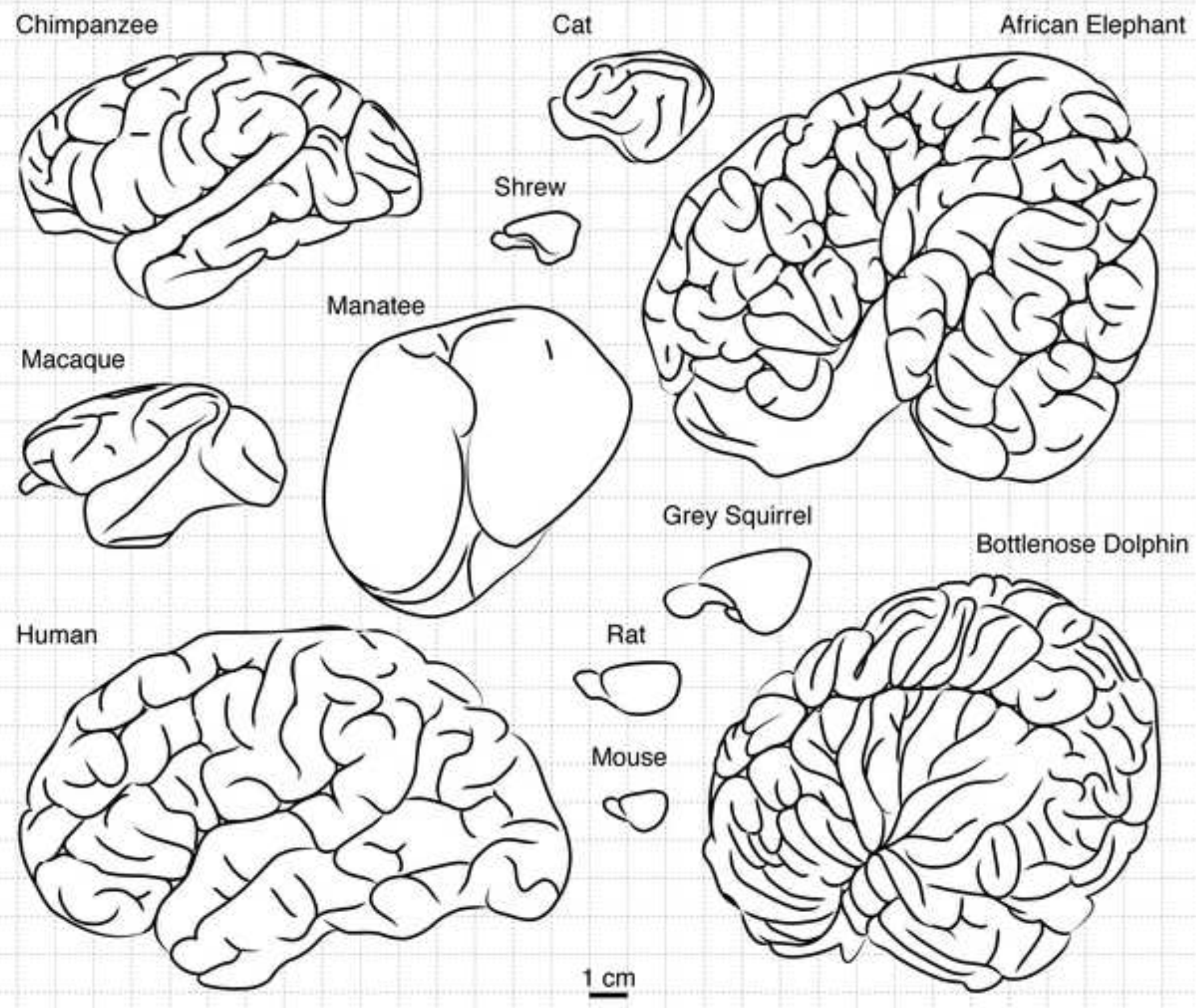


a

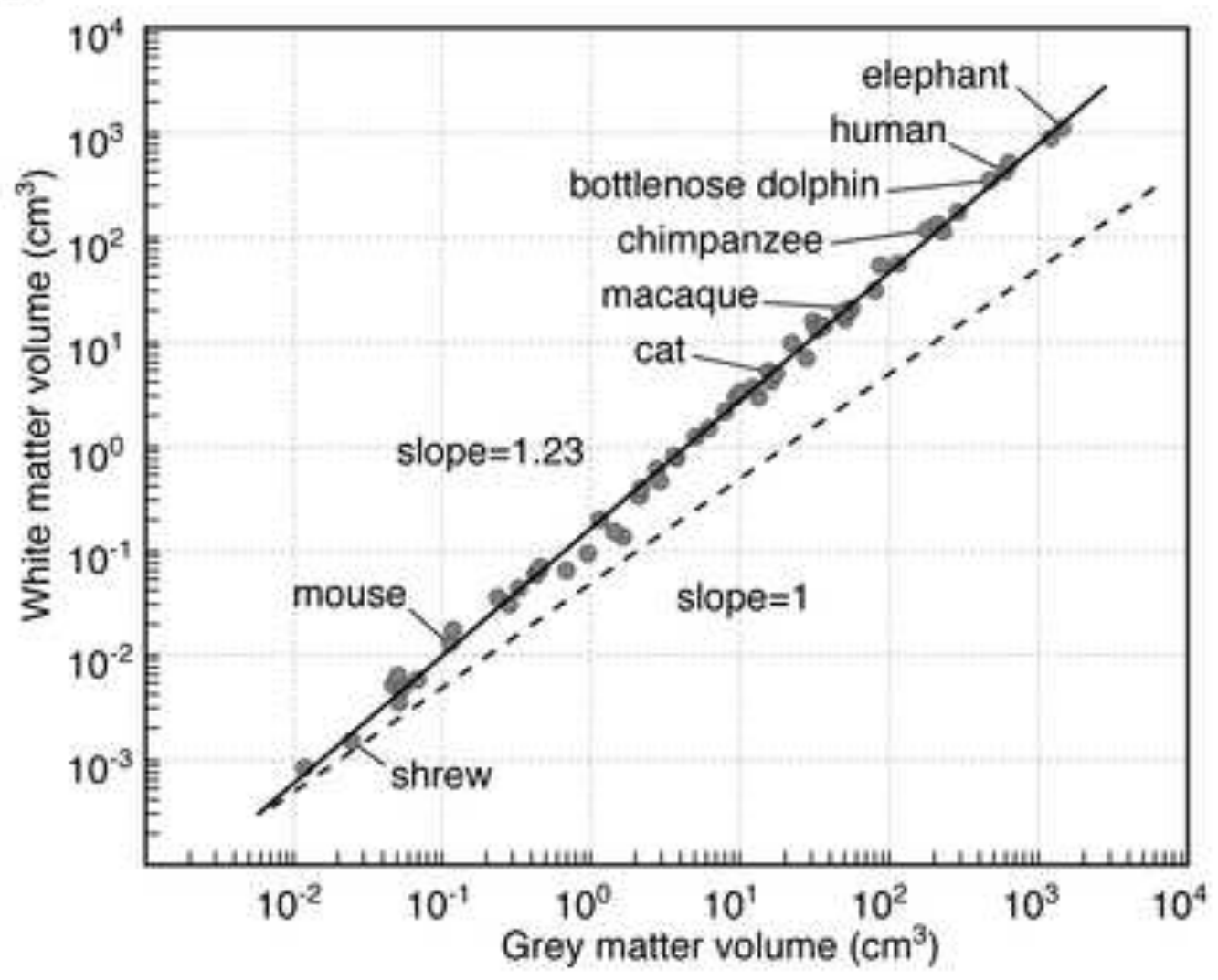

b

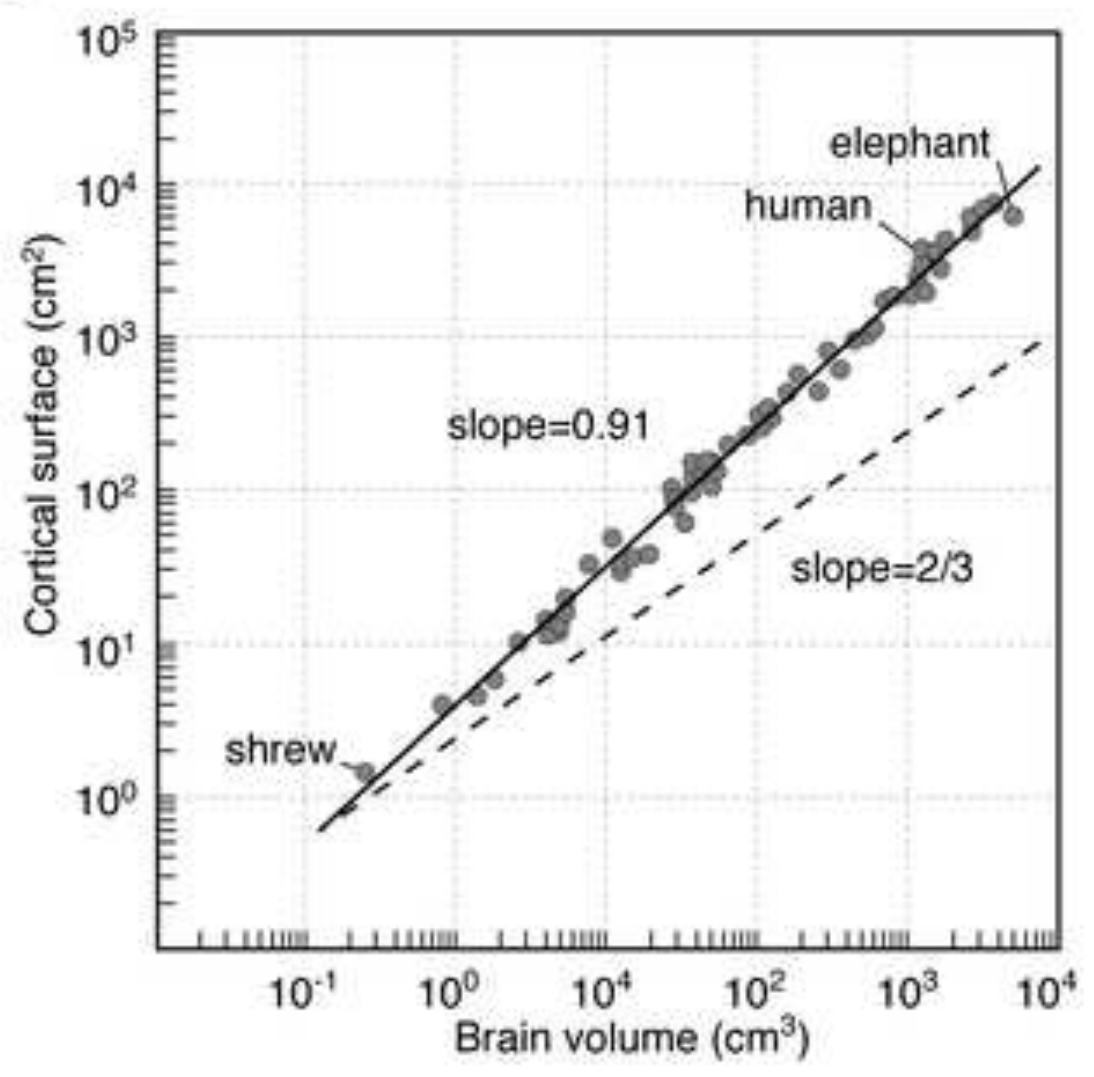




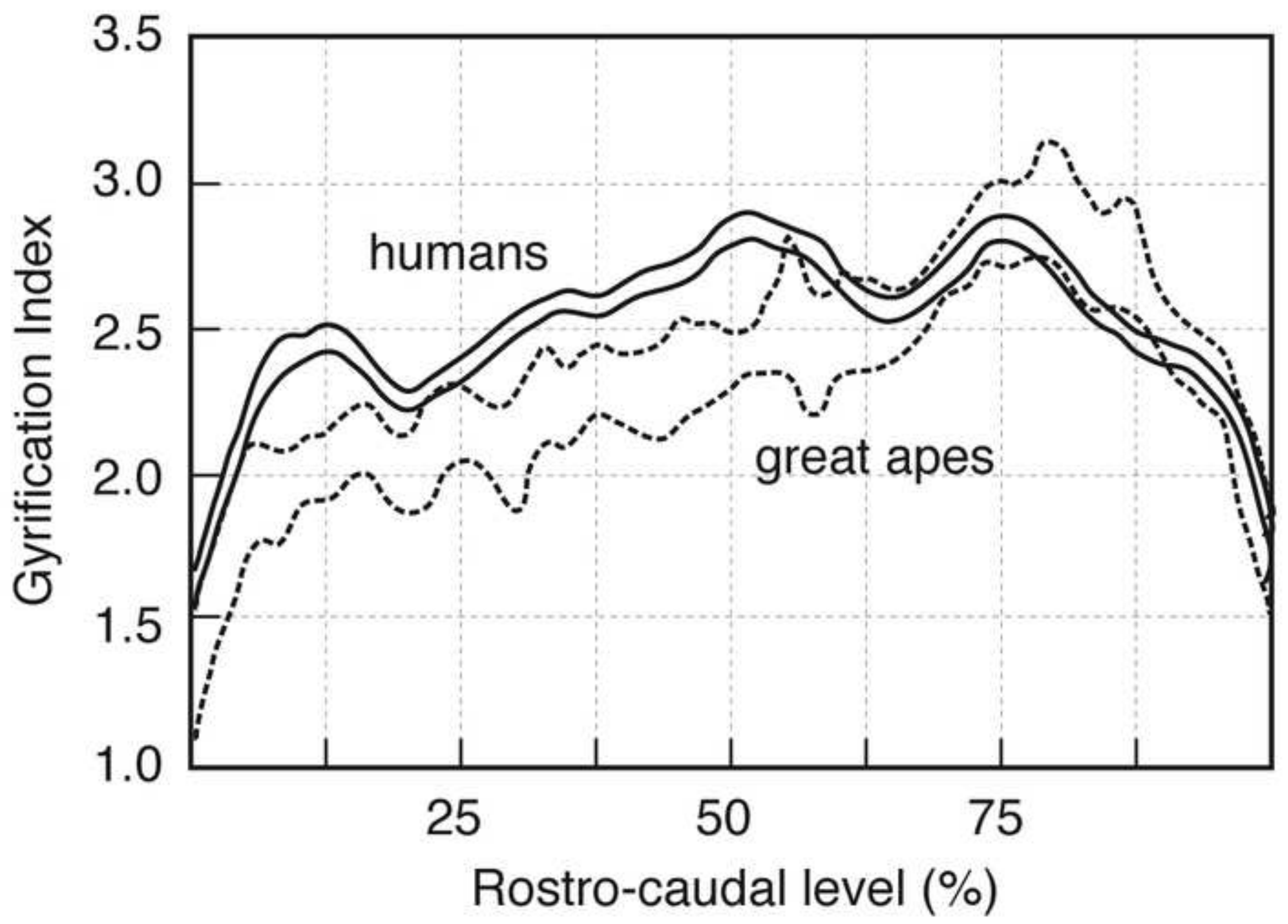




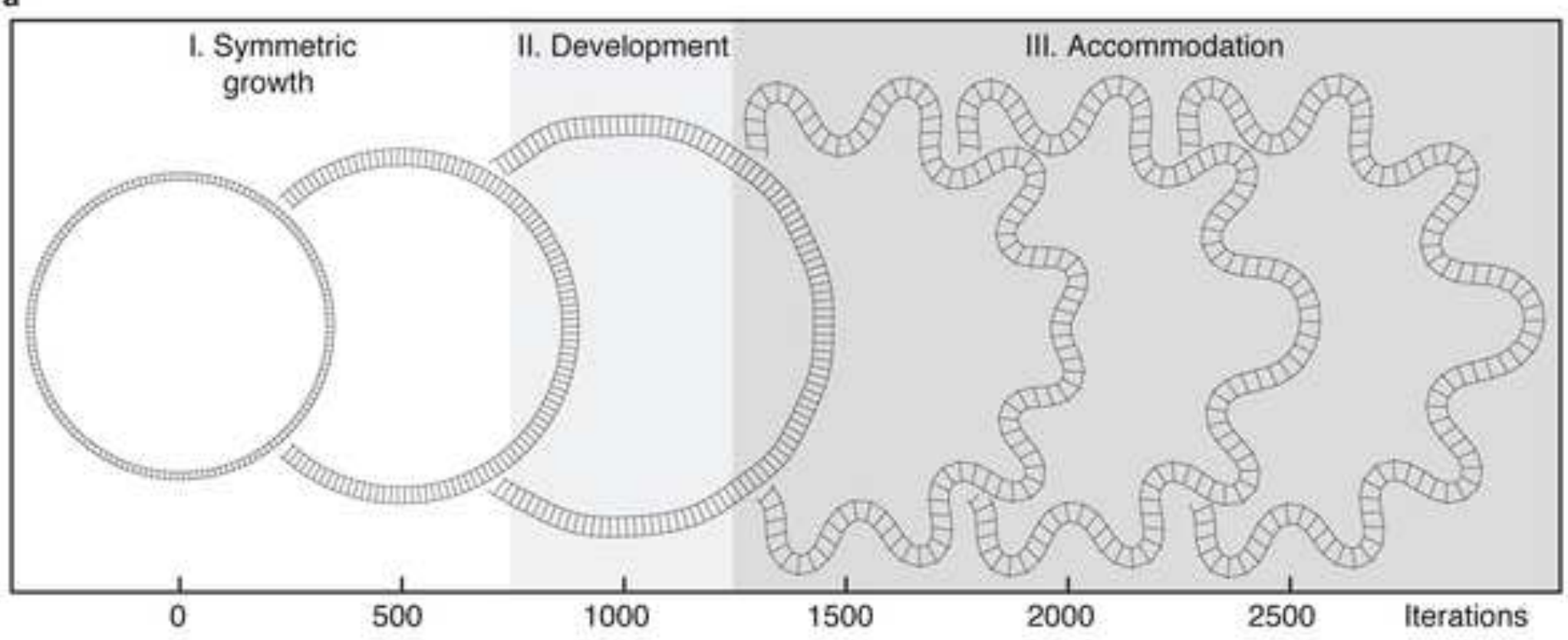

b

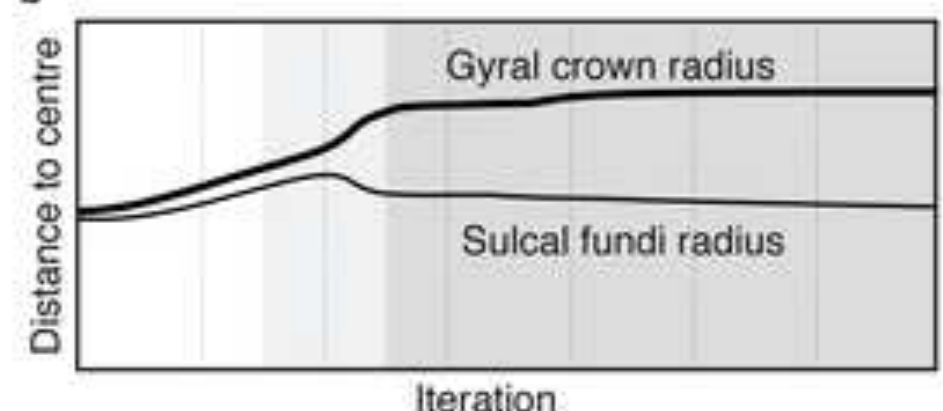

c

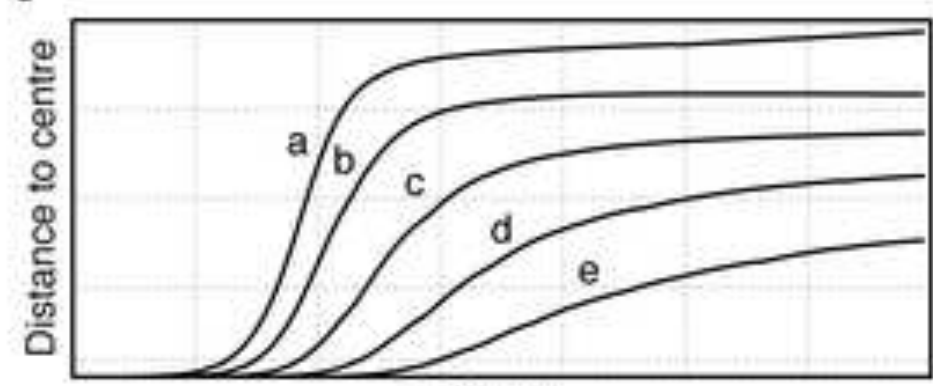

Iteration

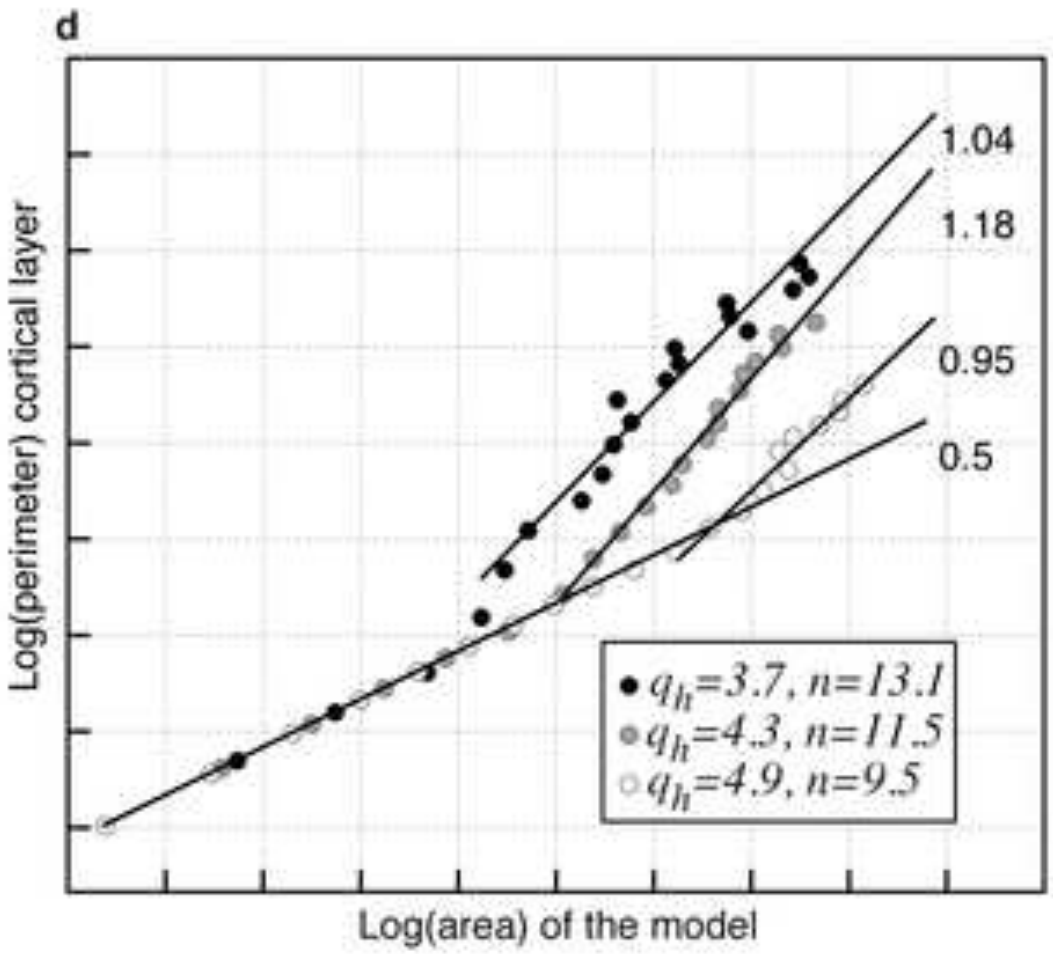


a
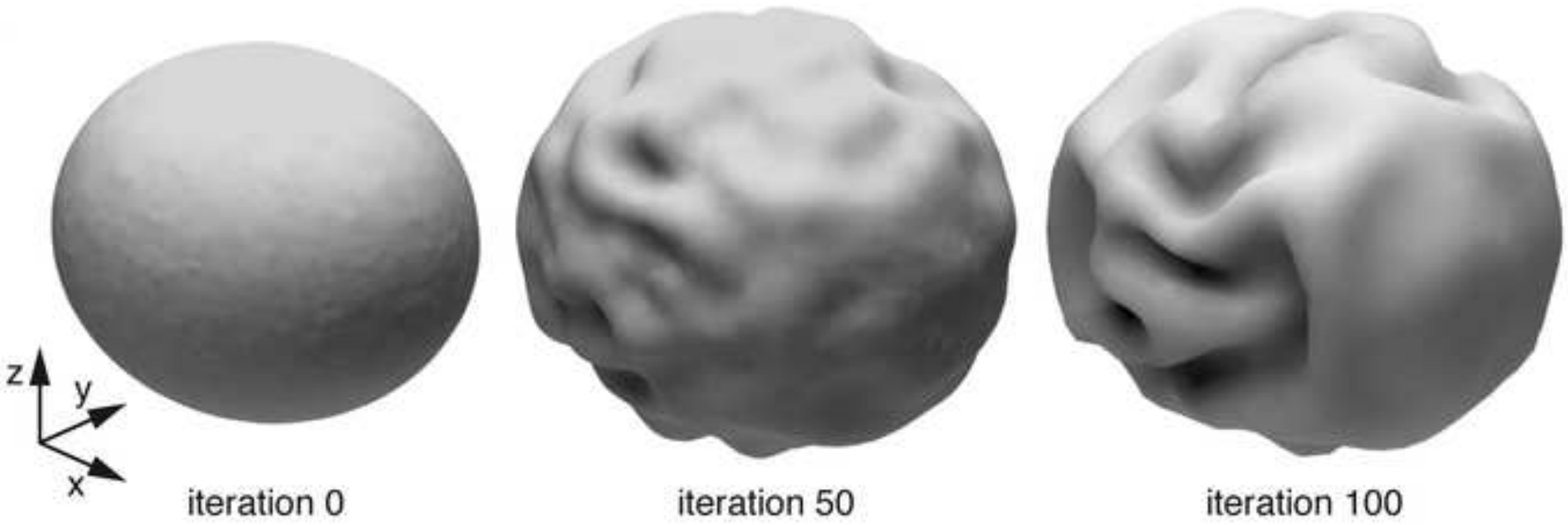

iteration 100

b
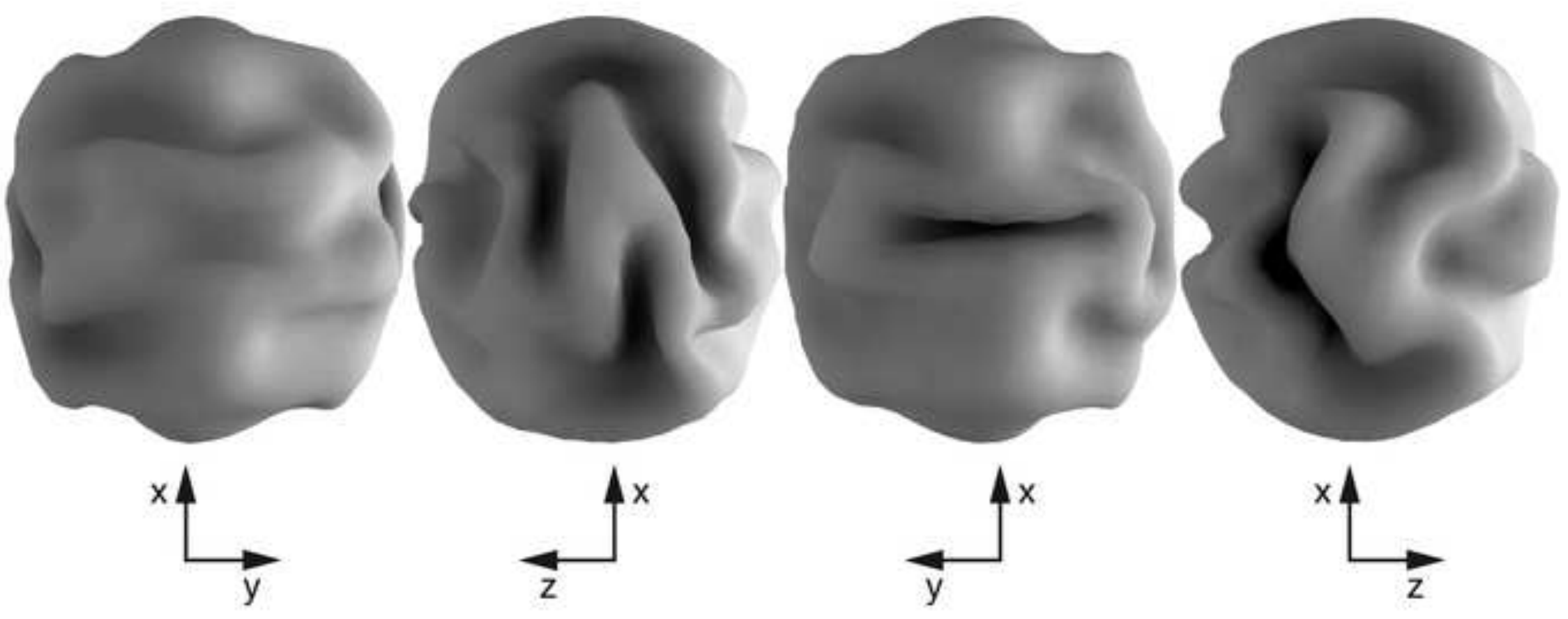


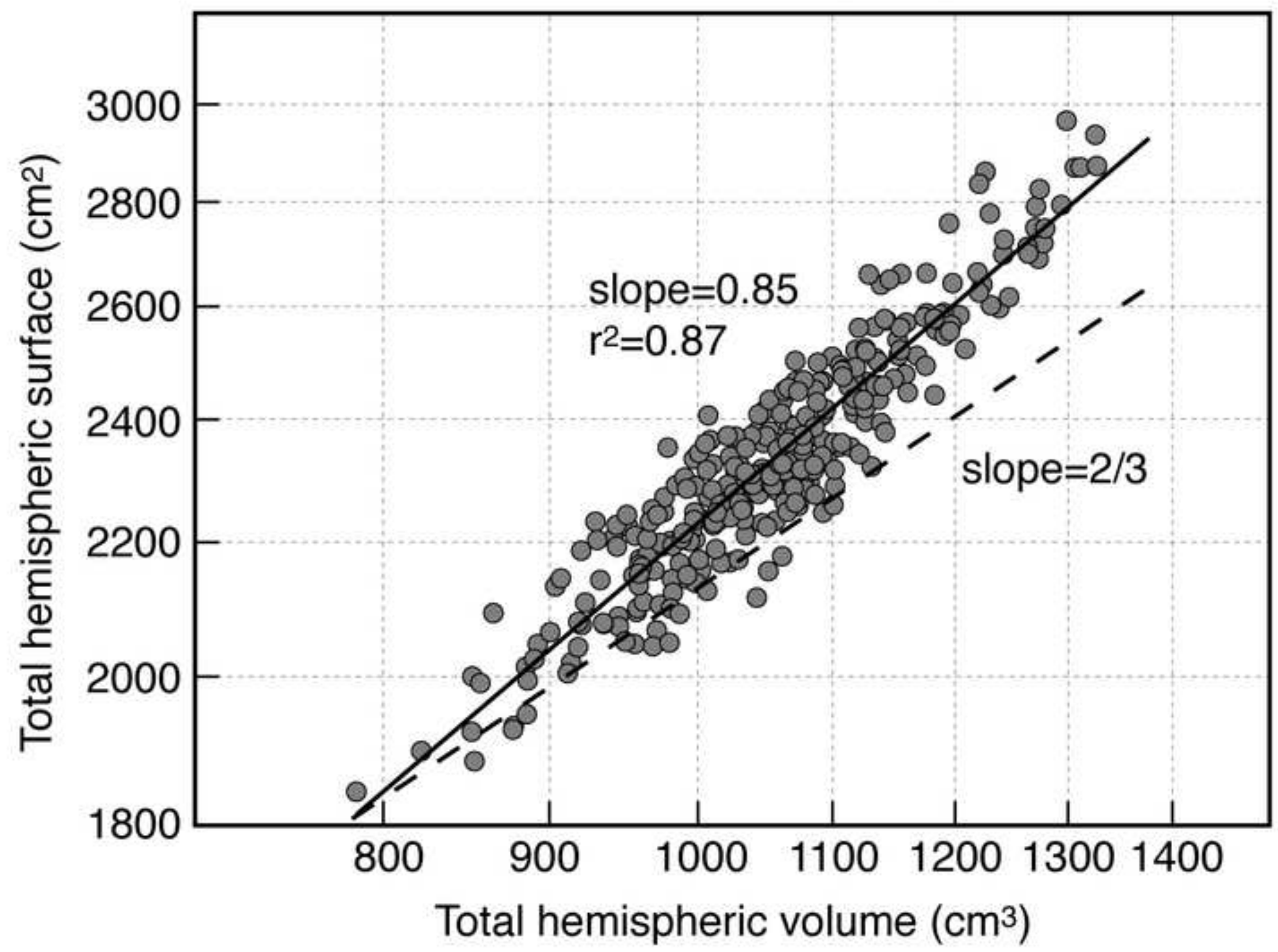



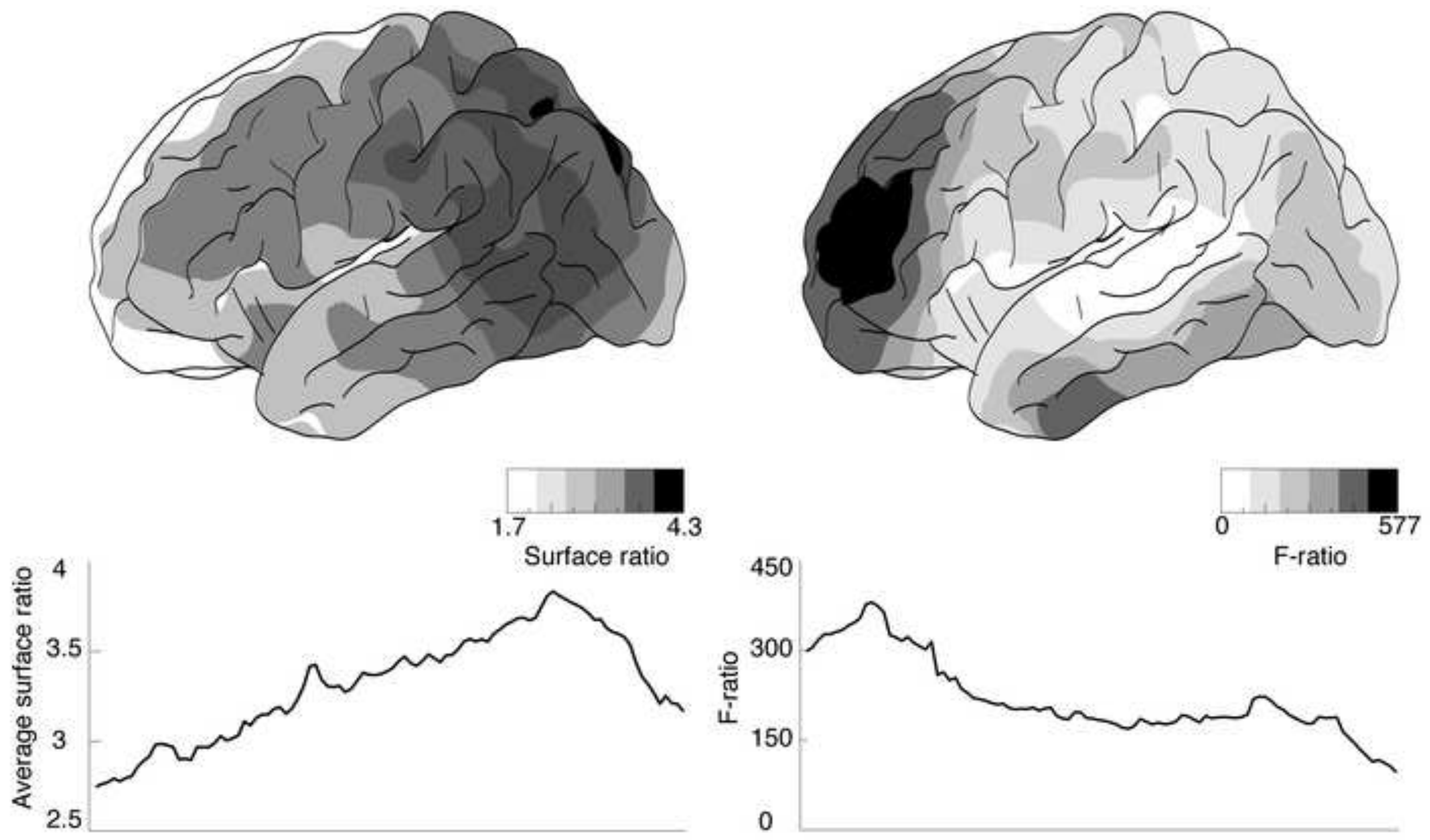
a
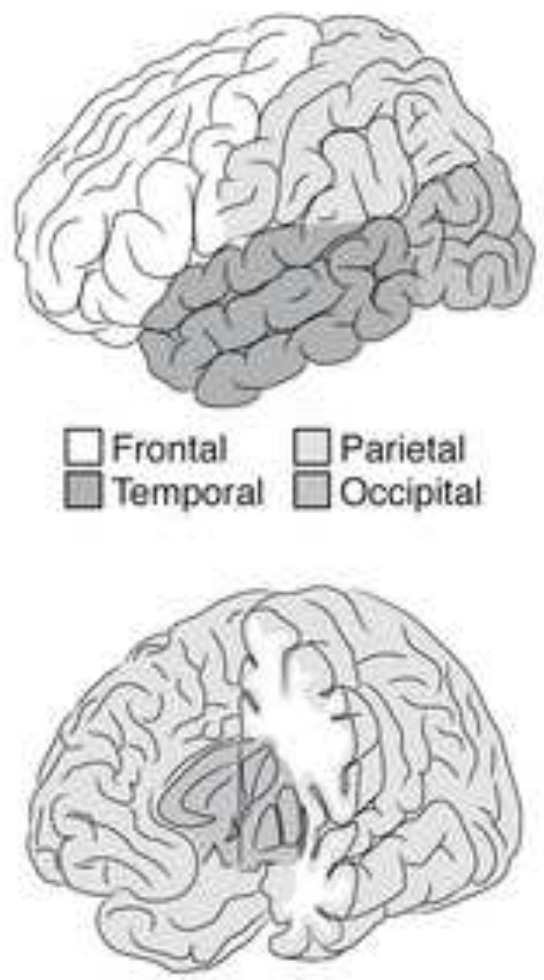

$\square$ Grey matter $\square$ White matter $\square$ Subcortical

c

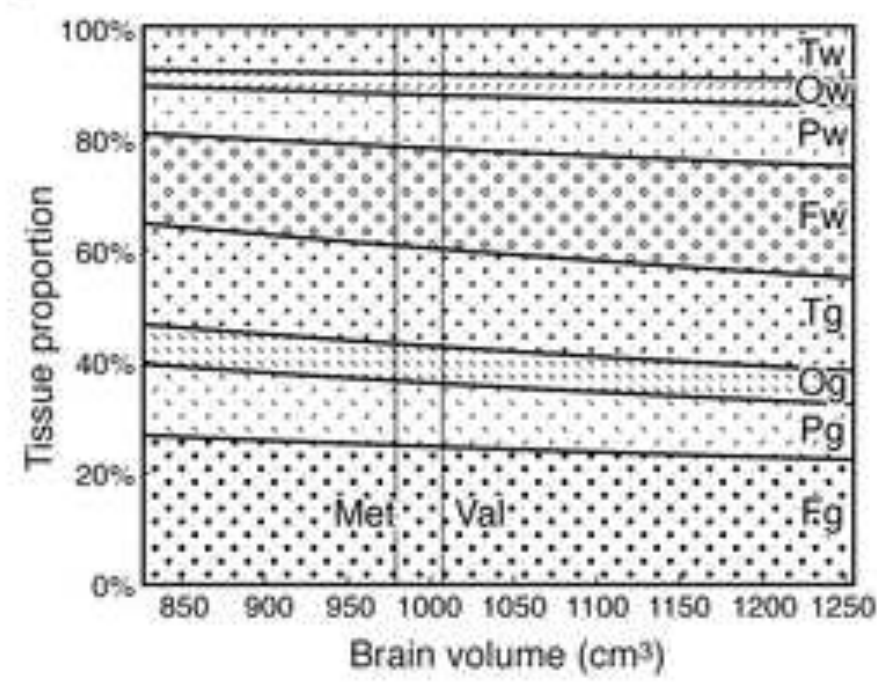

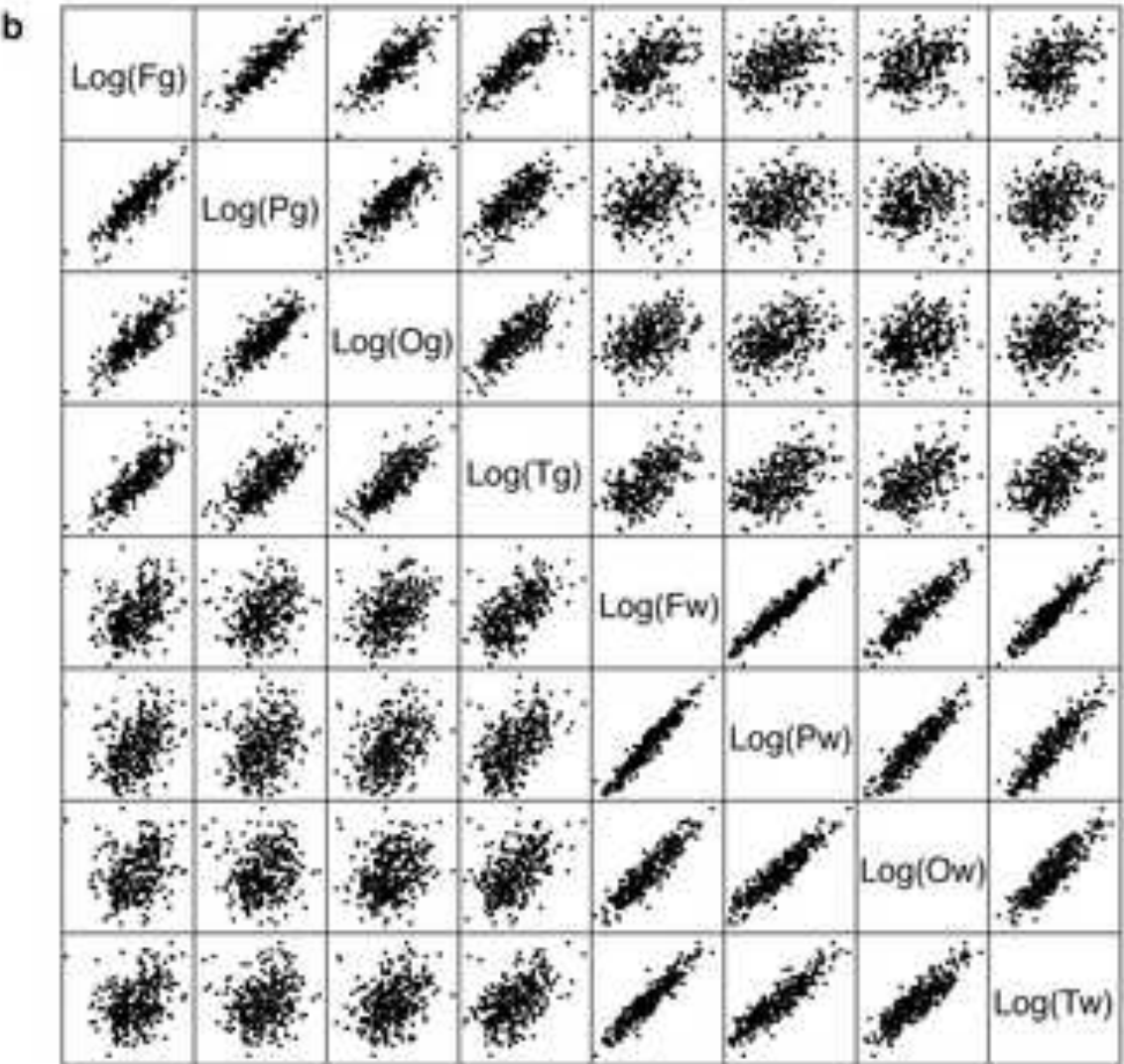

d

\begin{tabular}{|l|rrrrr|rrr|}
\hline & \multicolumn{5}{|c|}{ Observed } & \multicolumn{3}{c|}{ Expected } \\
Region & Met & \multicolumn{1}{|c}{ Val } & $\boldsymbol{\Delta}$ & $\mathbf{9 5 \%}$ & $\mathbf{C l}$ & Met & Val & $\boldsymbol{\Delta}$ \\
\hline Fw & 172.8 & 181.0 & 8.2 & {$[2.8$,} & $13.6]$ & 173.4 & 181.1 & 7.7 \\
Pw & 92.1 & 96.7 & 4.6 & {$[1.5$,} & $7.6]$ & 92.4 & 96.7 & 4.4 \\
Ow & 35.3 & 37.6 & 2.3 & {$[0.7$,} & $3.9]$ & 35.2 & 37.4 & 2.2 \\
Tw & 83.6 & 87.1 & 3.5 & {$[0.8$,} & $6.3]$ & 83.6 & 87.3 & 3.7 \\
Fg & 245.2 & 248.0 & 2.8 & {$[-2.6$,} & $8.2]$ & 244.3 & 248.3 & 4.0 \\
Pg & 113.6 & 114.3 & 0.7 & {$[-2.0$,} & $3.3]$ & 113.0 & 66.1 & 1.3 \\
Og & 64.4 & 66.6 & 2.1 & {$[0.6$,} & $3.7]$ & 65.0 & 66.1 & 1.1 \\
Tg & 172.0 & 176.2 & 4.2 & {$[0.2$,} & $8.1]$ & 172.4 & 176.2 & 4.0 \\
\hline
\end{tabular}

